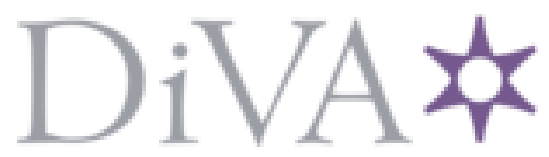

http://www.diva-portal.org

This is the published version of a paper published in Vård $i$ Norden.

Citation for the original published paper (version of record):

Fridlund, B., Billing, E. (2002)

Cardiac rehabilitation and psychosocial gender differences.

Vård i Norden, 22(3): 48-51

Access to the published version may require subscription.

N.B. When citing this work, cite the original published paper.

Permanent link to this version:

http://urn.kb.se/resolve?urn=urn:nbn:se:hh:diva-3389 


\section{Cardiac Rebabilitation and Psychosocial Gender Differences}

\section{Bengt Fridlund, RN RNT PhD professor Ewa Billing, RN PhD assisting professor}

$\begin{array}{ll} & \text { nature sometimes interact, trig- } \\ & \text { gering the onset of heart disease. } \\ \text { ABSTRACT } & \text { These interacting factors are }\end{array}$
Tertiary prevention comprising commonly referred to as risk factreatment, care and rehabilitation of patients with heart disease is an important task for nurses and other health care professionals. This is achieved through a combination of medico-physical and psychosocial interventions, related to the male or female patient's personal, expressed pro-

blems and the personnel's knowledge. Therefore, the aim of this literature study was to highlight the comprehensiveness of the cardiac rehabilitation concept from a Nordic perspective and with focus on psychosocial gender differences. The Nordic examples of cardiac rehabilitation programmes, involving a multidisciplinary team and comprising health education, physical exercise and stress management, include no specific efforts for women. However, the efficacy of out-patient programmes is still poorly documented and there is a need to increase the attendance of eli-

gible patients, particularly women, in these programmes.

There are differences between the genders concerning the need for support from personnel and laymen in order to better reach patient's compliance. Taking the psychosocial characteristics specific to women into account, could be the first step towards increased attendance rates for women as well as reaching the proximal and distal targets with regards to cardiac rehabilitation.

KEY WORDS: cardiac rehabilitation, CHD, compliance, gender, interdisciplinary, multifactorial, prevention, psychosocial,

\section{Introduction}

Today we know that factors of a biophysical, emotional and social nature sometimes interact, trigtors. However, this explanation does not reflect the whole truth, as not all individuals who are exposed to one or several risk factors develop heart disease. One explanation is that some people are more vulnerable to heart disease than others. ${ }^{2}$ Another explanation is that some people surround themselves with factors that protect them from disease, so-called health factors, like a strong social network including social integration and attachment. ${ }^{3}$ Individuals become vulnerable to disease when the demands on them grow too large in relation to their resources. They then experience discordance in their relationship with their surroundings. Such a situation can trigger heart disease in some individuals, even at an early age. Clinical manifestations, such as angina pectoris and myocardial infarction, caused by psychosocial factors are documented in both men and women from the age of $40 . .^{4-6}$

Disease prevention, therefore, either through primary prevention (early detection) or secondary prevention (taking measures to counteract the disease process), constitute an extremely importan ease is well established and diagnosed in a man or woman, its effects have to be counteracted by starting so-called tertiary prevention, comprising treatment, care and rehabilitation. Again, this is an important task for nurses, especially for the cardiovascular nurse. ${ }^{8,9}$ This is achieved through a combination of medico-physical and psychosocial interventions related to the patient's (and partner's) personal, expressed problems and the personnel's knowtask for nurses. ${ }^{7}$ When heart dis- ledge. ${ }^{6,10,11}$ The objective of these interventions is to avoid further manifestations of the heart disease and to increase quality of life (QoL). Thus, the tertiary preventive interventions are intended to improve the effect of the acute treatment actions and to avoid or prevent risk factors (proximal targets), thereby improving the patient's QoL and/or avoiding mortality (distal targets). ${ }^{12}$ Therefore, the aim of this study was to highlight the comprehensiveness of the cardiac rehabilitation concept from a Nordic perspective and with focus on psychosocial gender differences.

\section{The review process}

The scientific review process started by searches in the computerised sources of MEDLINE and CINAHL. As the researchers are cardiovascular nurses with special interests in multifactorial tertiary prevention, the literature should contain information regarding the importance of comprehensive rehabilitation (CR) with focus on psychosocial gender differences. The search words used were: cardiac rehabilitation, coronary heart disease, gender, interdisciplinary, intervention, multifactorial, prevention and psychosocial; alone or in combination. The inclusion criteria were that the articles were published in peer review journals, written in English and published during the latest decade. The systematic search gave 46 original articles, of which 31 had special focus on gender differences. After reviewing the articles, the consensus was that the special focus on psychosocial gender differences should comprise «psychosocial characteristics on the patient's introduction to CR» and «the psychosocial characteristics of CR participation». In this connection all articles were analysed by content and categorised.

\section{Cardiac rehabilitation: defini- tion, content and meaning}

The World Health Organisation's definition of rehabilitation of cardiac patients dating from 1993 is both well-known and well recognised. It defines rehabilitation as the sum of the activities needed to provide the optimal physical, mental and social preconditions for regaining a normal function in society. The key components of such a programme are: 1) initial evaluation and risk assessment, 2) identification of specific goals for each risk factor, 3) formulation and implementation of an individualised treatment plan that includes lifestyle modification and pharmacological interventions for accomplishing specific risk reduction goals, 4) long-term follow-up to enhance compliance and revise the treatment plan as indicated, and 5) a mechanism for outcomes based on long-term assessment of each patient. ${ }^{13}$ Accordingly, the rehabilitation activities do not take place all at once, but are carried out in different time periods, so-called phases. ${ }^{14}$ The first phase includes all the rehabilitative actions that are made during the journey by ambulance to hospital and, subsequently, at the hospital. The second phase starts when the individual leaves hospital. It covers the following 3-6 months until the patient is more physically independent and can start the long-term life changes needed. The third phase covers the rest of a person's life. It focuses on retaining and maintaining physical and psychological ability as well as avoiding risk factors in the person's life style. Cardiac rehabilitation is of multidisciplinary concern, as it includes a combination of medico-clinical and psycho-social interventions (or psycho-educational interventions) aimed at reducing the risk factors and improving the health factors, thereby reducing the risk of a relapse. ${ }^{15}$ Furthermore, in the 
education of the patient (and partner), it is important to know his or her learning needs. ${ }^{6}{ }^{16}$ Today there seems to be a difference regarding what the health care professionals point out as vital for the patient in the recovery process and what the patient finds important. ${ }^{17}$ Hence, these interventions need to be tailored to the individual in order to achieve greater patient compliance.

\section{The comprehensive rehabilita- tion programmes of today; the Nordic approach}

During the 1990s, the strategy used in the Nordic countries for $\mathrm{CR}$ programmes has been changed to also include a holistic approach to the life situation of patients with heart disease..$^{18,19}$ This calls for a follow-up comprising both short-term and longterm life style changes, i.e. rehabilitation phases 1 and 2. However, the core of these programmes remains the provision of informative support by the personnel. This support should be in the form of general counselling and education, so-called «heart schools», follow-up care activities and structured out-patient cardiac rehabilitation activities, e.g. hospital-based programmes, home programmes or organisational-based programmes, which are intensified during phases 23. ${ }^{20-23}$ Several groups of patients with heart failure, as well as those treated with PTCA/CABG, are today offered their 'own' programmes, which are tailored both physically and emotionally to the specific situation related to the disease. ${ }^{24-27}$

Due to the physician-supervised, nurse case-manager models, or what in everyday speech is called nurse-led rehabilitation or the «spider in the web» role, ${ }^{3}$ the $\mathrm{CR}$ programmes are becoming more and more comprehensive. Today, they include both health education and physical exercise, as well as social support and stress management. ${ }^{27}$ This 'smorgasbord' thinking ${ }^{27}$ does not always exactly fit the holistic idea. In addition to «get-going» groups and physical exercise, it comprises, in most cases, courses focusing on the management of diet, crisis, emotional distress, smoking cessation and stress. Many of the courses draw on the dynamic forces of the collective group. Patients with heart disease support each other in difficult situations and in making difficult choices. The personnel regularly involved in cardiac rehabilitation are cardiovascular nurses, dieticians, cardiologists, physiotherapists and social workers. ${ }^{27,28}$ The programmes can vary in length but last, on average, about three months, irrespective of content. This is because of the importance of starting the necessary life style changes early. The county councils are increasingly transferring cardiac rehabilitation from the inpatient to the primary care already by phase 2 of the rehabilitation programme. Today both private companies and patient associations are offering successful outpatient non-hospital-based comprehensive programmes. ${ }^{29,30}$ However, despite this clinical and theoretical knowledge, there is no documentation to date in the Nordic countries regarding women's' cardiac rehabilitation programmes and their outcomes, but there are several ongoing studies.

\section{Gender differences in psycho- social characteristics on the patient's introduction to $\mathrm{CR}$}

Even though the risk factors for developing heart disease are the same for men and women, the impact of these factors is different. This is especially true for women with regards to diabetes, high blood lipids and smoking, as these risk factors seem to be even more dangerous for women than for men. ${ }^{31,32}$ The unfavourable risk profile, or more correctly expressed, health profile, of women in combination with older age results in increased mortality for women compared to men. However, the knowledge of the female risk profile is still unsatisfactory, because most research into risk factors and prediction of heart disease has been conducted on men. ${ }^{32,33}$ During the last two decades, there has been increasing evidence that not only the traditional risk factors but also the psychosocial factors are important in the progress of the disease, especially in women. However, this evidence has not been satisfactorily investigated. ${ }^{34-38}$ One reason often mentioned for psychosocial factors not being included in traditional risk factor equations is the lack of models showing mechanisms by which these factors involve an increased risk. ${ }^{39}$ Psychosocial factors are often clustered into a profile or characteristics. The most established characteristics are working (e.g. education, occupation, double loads of work and family), psychological (e.g. anxiety, depressive symptoms, meaningfulness, vital exhaustion), behavioural (e.g. coping mode, type A behaviour, health locus of control, sleeping habits), and social (e.g. social integration, attachment, social strain, social support/isolation). In the case of psychosocial factors, evidence is scarce, which means that caution has to be taken when it comes to making generalisations. However, there seem to be gender differences regarding increased multiple stressors before onset of heart disease, i.e. both at work and at home, due to strain at the present job and too little time for relaxation. ${ }^{40}$ Lack of opportunity for growth and development at work as well as during leisure time poses a risk. The most pronounced problems for both genders seem to be mental strain at work, anxiety, depressive symptoms, sleep problems, lack of social integration and fewer social activities. ${ }^{34,41-43}$ Besides traditional risk factors, men with heart disease are more vulnerable to psychosocial factors, on the whole exhibiting more psychosocial problems than women do. On the other hand, anxiety, vital exhaustion and less social activities seem to be especially pronounced in women. . $^{63,44,45}$ Social support needs do not appear to differ between genders at the time of initial evaluation and risk assessment (the diagnosis), i.e. rehabilitation phase 1 , when both genders report that they wish to receive emotional support. Men want support from their partners, while women want support from their next-of-kin, i.e. more often from sisters and children than partners. ${ }^{46}$ Furthermore, men want education from nurses, while women prefer physicians as their educators. ${ }^{47}$ The physician's recommendation is the most important factor influencing both men's and women's decision to participate in rehabilitation programmes. The second most important factor for attending $\mathrm{CR}$ programmes is encouragement from family members. This is especially true for women whose adult children encourage them to attend. Women also find, to a greater extent than men, concomitant illness to be a significant barrier to participating in $\mathrm{CR}$ programmes. This is also true of personal and social barriers (time urgency and social stress). ${ }^{48}$ Furthermore, men have higher eligibility rates for phase 1 , whereas women have higher rates for phase 2 , and more men receive a referral for phase 2 from their physicians compared to women. ${ }^{49}$

\section{Gender differences in the psychosocial characteristics of CR participation}

In spite of the knowledge that cardiac rehabilitation promotes several health benefits among patients with heart disease, a considerable proportion of eligible 
patients are non-attenders. This is especially true for women, ${ }^{40,50}$ who have a participation rate of between 10 and 50\%. Furthermore, men have a higher completion rate for phase 2 compared to women. For patients, and especially for women who choose not to attend a phase 2 programme, the most common reasons are transportation problems, having exercise equipment at home, and insurance problems. ${ }^{49}$ The female non-attenders are older and more likely to be single as well as exhibiting more traditional risk factors compared to their male counterparts. Low attendance by women gives the impression that they are less motivated and therefore less compliant when it comes to $\mathrm{CR} .{ }^{51}$ High attendance is related to a stronger belief that the illness can be cured or controlled. However, the efficacy of different $\mathrm{CR}$ programmes needs to be further investigated. Failure to reduce emotional distress leads to failure to reduce mortality or CHD recurrences, as well as failure to increase QoL. ${ }^{52,53}$ Still, hospital-based out-patient programmes seem to be more efficient than home programmes or primary programmes, but this evidence is poorly supported. Women who take part in home programmes show no improvement with regards to cardiac knowledge or lifestyle changes in terms of exercise compliance and stress control. ${ }^{54}$ Similar changes, especially regarding type $\mathrm{A}$ behaviour, have been shown to result from a primary care intervention. ${ }^{55}$ In outpatient hospitalbased programmes, the general view is that men show an overall better QoL compared to women. ${ }^{56}$ In particular, younger and older women exhibit more symptoms of depression, receive less social support and participate less in therapeutic exercise and CR. However, women who complete CR seem to achieve greater lipid benefits and engage in physical exercise over longer periods of time compared to men..$^{40,57}$ Social support needs also seem to differ between genders, in that men have informative needs while women ask for material and belongingness support. ${ }^{46}$ Furthermore, it is pointed out that CR programmes that are successful regarding proximal targets, such as smoking behaviour, physical exercise and emotional stress, are also more effective regarding distal targets, such as cardiac mortality and MI recurrence, compared to programmes without success regarding proximal targets. ${ }^{12}$

\section{Conclusions}

Cardiac rehabilitation in the Nordic countries today is comprehensive as well as multidisciplinary in nature. The cardiovascular nurse plays the role of «spider-in-the web» in the rehabilitation process. However, the efficacy of outpatient cardiac rehabilitation programmes is still poorly documented, and there is a need to increase attendance in the CR programmes by eligible patients, particularly women and elderly people. Low attendance gives the impression that these patient groups are less motivated and therefore less compliant when it comes to cardiac rehabilitation. Programmes, especially psychosocial ones, which fail to reduce proximal targets (e.g. emotional distress), also fail to lead to reduced distal targets (e.g. mortality). Psychosocial gender differences exist concerning support needs from personnel and laymen in order to reach patient's compliance. It is therefore important to design personalised or gender-specific programmes for heart disease patients.

\section{Clinical and research implications}

In the future, cardiovascular nurses and other health care professionals need to learn more from the psychosocial sciences in order to reach an acceptable level of patient compliance. This knowledge has to be used to build programmes that are effective (e.g. fewer drop-outs) regarding practical (e.g. long distance travelling), emotional (e.g. anxiety) and cognitive (e.g. learning needs) conditions for all patients with heart disease, including elderly people and women. Evaluation tools for studying the effectiveness of the programmes need to be developed further, and more studies need to be performed concerning psychosocial gender differences. Studies with a qualitative design are especially required in order to gain a deeper understanding of patients' thoughts and feelings during the rehabilitation process.

\section{Bengt Fridlund, RN RNT PhD} professor (1) and Ewa Billing, $\mathrm{RN} \mathrm{PhD}$ assisting professor (2)

(1) School of Social \& Health Sciences, Halmstad University, Halmstad and Dept of Nursing, Lund University, Sweden

(2) Karolinska Institutet, Division of Internal Medicine, Danderyd Hospital, Danderyd, Sweden

Correspondence to: Prof Bengt Fridlund, School of Social \& Health Sciences, Halmstad University, POBox 823, 30118 Halmstad, SWEDEN; e-mail bengt.fridlund@hos.hh.se

\section{References}

1. Medich CJ, Stuart E, Chase SK. Healing through integration: promoting wellness in cardiac rehabilitation. J Cardiovasc Nurs. 1997;11:6679.

2. Lidell E, Fridlund B, Segesten K. Vulnerability factors from a pre- and post-myocardial perspective: a qualitative analysis. Cor Health Care. 1998;2:72-80.

3. Fridlund B. Editorial. Scand J Caring Sci. 2000;14:1-4.
4. LaCharity LA. The experiences of younger women with coronary artery disease. J Womens Health Gend Based Med. 1999;8:773-785.

Drory Y, Kravetz S, Weingarten M. Comparison of sexual activity of women and men after first myocardial infaction. Am J Cardiol. 2000;85:1283-1287.

6. Svedlund M, Axelsson I. Acute myocardial infarction in middle-aged women: narrations from the patients and their partners during rehabilitation. Int Crit Care Nurs. 2000;16:246265.

7. Toobert DJ, Glasgow RE, Nettekoven LA, Brown JE. Behavioral and psychosocial effects of intensive lifestyle management for women with coronary heart disease. Patient Educ Couns. 1998;35:177-188.

8. Jolly K, Bradley F, Sharp S, Smith H, Mant D. Follow-up care in general practice of patients with myocardial infarction or angina pectoris: initial results of the SHIP trial. Southampton Heart Integrated Care Project. Fam Pract. 1998;15:548-555.

9. Nolan M, Nolan J. Cardiac rehabilitation following myocardial infarction. Br J Nurs. 1998;11:219-225.

10. Jaarsma T, Kastermans M, Dassen T, Philipsen H. Problems of cardiac patients in early recovery. J Adv Nurs. 1995;21:21-27.

11. Newens AJ, McColl E, Bond S, Priest JF. Patients' and nurses' knowledge of cardiac-related symptoms and cardiac misconceptions. Heart Lung. 1996;25:190-199.

12. Dusseldorp E, van Elderen T, Maes S, Meulman J, Kraaij V. A meta-analysis of psychoeducational programs for coronary heart disease patients. Health Psych. 1999;18:506519.

13. Gordon NF, Haskell WL. Comprehensive cardiovascular disease risk reduction in a cardiac rehabilitation setting. Am J Cardiol. 1997;80:69H$73 \mathrm{H}$.

14. Fridlund B. The role of the nurse in cardiac rehabilitation programmes. Eur J Cardiovasc Nurs. 2002;1:4-8.

15. Rutledge JC, Hyson DA, Garduno D, Cort DA, Paumer L, Kappagoda CT. Lifestyle modification program in management of patients with coro- 
nary artery disease: the clinical experience in a tertiary care hospital. J Cardiopulm Rehabil. 1999;19:226234.

16. Billing E, Bar-On D, Rehnqvist N. Determinants of life style changes after a first myocardial infarction. Cardiology. 1997;88:29-35.

17. Egan F. Cardiac rehabilitation into new millennium. Int Crit Care Nurs. 1999;15:163-168.

18. Fridlund B. A holistic framework for nursing care: Rehabilitation of the myocardial infarction patient. J Hol Nurs. 1994;12:204-217.

19. Bethell HJ. Cardiac rehabilitation: from Hellerstein to the millennium. Int J Clin Pract. 2000;54:92-97.

20. Hedback B, Perk J, Wodlin P. Long-term reduction of cardiac mortality after myocardial infarction: 10 years results of a comprehensive rehabilitation programme: Eur Heart J. 1993;14:831-835.

21. Lidell E, Fridlund B. Long-term effects of a comprehensive rehabilitation programme after myocardial infarction. Scand J Caring Sci. 1996;10:67-74

22. Maeland JG, Havik OE. After the myocardial infarction. A medical and psychological view with special emphasis on perceived illness. Scand J Rehabil Med. Suppl 1989;22:1-87.

23. Hamalainen H, Luurila OJ, Kallio V, Knuts LR. Reduction in sudden deaths and coronary mortality in myocardial infarction patients after rehabilitation. 15 year follow-up study. Eur Heart J. 1995;16:18391844.

24. Ekman I, Norberg A, Lundman B. An intervention aimed at reducing uncertainty in elderly people with chronic heart failure. Int J Human Caring. 2000;4:7-13.

Hoffman-Bang C, Svane B, Lisspers J et al. Two-year results of a controlled study of a residential rehabilitation programme for patients with percutaneous transluminal coronary angioplasty: a randomised study of a multifactorial programme. Eur Heart J. 1999;20:1465-1474.

26. Engblom E, Korpilahti K, Hamalainen H, Ronnemaa T, Puuka P. Quality of life and return to work 5 years after coronary artery bypass surgery. Long-term results of cardiac rehabilitation. J Cardiopulm Rehabil. 1997;17:29-36

27. Wieslander I, Fridlund B. Cardiac rehabilitation efforts for patients with ischaemic heart disease - a 5-year comparative review in five counties in western Sweden. Cor Health Care. 2001;5:16-24

28. Fridlund B and the MISS-W Study Group. Self-rated health in women after their first myocardial infarction: A 12-month comparison between participation and nonparticipation in a cardiac rehabilitation programme. Health Care Women Int 2000;21:727-738.

29. Lisspers J, Hoffman-Bang C, Nordlander R et al. Multifactorial evaluation of a programme for lifestyle behaviour change in rehabilitation and secondary prevention of coronary artery disease. Scand Cardiovasc J. 1999;33:9-16.

30. Hildingh C, Segesten K, Bengtsson C, Fridlund B. Experience of social support among participants in self-help groups related to coronary heart disease. J Clin Nurs. 1994;3:219-226.

31. Schenck-Gustafsson K. Risk factors for cardiovascular disease in women: assessment and management. Eur Heart J. 1996;17:2-8.

32. Thomas RJ, Miller NH,

Lamendola C, et al. National survey on gender differences in cardiac rehabilitation programs. Patient characteristics and enrollment patterns. J Cardiopulm Rehabil. 1996;16:402412.

33. Brezinka V, Dusseldorp E, Maes $\mathrm{S}$. Gender differences in psychosocial profile at entry into cardiac rehabilitation. J Cardiopulm Rehabil. 1998;18:445-449.

34. Welin A, Rosengren A, Wilhelmsen L. Social relationships and myocardial infarction: a case control study. J Cardiovasc Risk. 1995:3:183-190

35. Arnold E. The stress connection. Women and coronary heart disease. Crit Care Nurs Clin North Am. 1997;9:565-575.

36. Billing E, Hjemdahl P, Rehnqvist N. Psychosocial variables in female versus male patients with stable angina pectoris and matched controls. Eur Heart J. 1997;18:910-917.

37. Con AH, Linden W, Thompson JM, Ignaszewski A. The psychology of men and women recovering from coronary artery bypass surgery. $\mathrm{J}$ Cardiopulm Rehabil. 1999;19:152161

38. Wamala SP, Mittleman MA, Horsten M, Schenck-Gustafsson K, Orth-Gomér K. Job stress and the occupational gradient in coronary heart disease risk in women. The Stockholm Female Coronary Risk Study. Soc Sci Med. 2000;51:481489

39. Fridlund B and the MISS-W Study Group. Health in women after their first myocardial infarction: A holistic perspective of cardiac rehabilitation phase 3. Cor Health Care. 1997;1:94-100

40. Brezinka V, Kittel F. Psychosocia factors of coronary heart disease in women: a review. Soc Sci Med. 1996;42:1351-1365.

41. Welin C, Rosengren A, Wedel H, Wilhelmsen L. Psychological characteristics in patients with myocardial infarction: a case control study. Cardiovasc Risk Fact. 1994;4:154161.

42. Welin C, Rosengren A, Wedel H, Wilhelmsen L. Myocardial infarction in relation to work, family and life events. Cardiovasc Risk Fact. 1995;5:30-38.

43. Lukkarinen H, Hentinen M. Assessment of quality of life with Nottingham Health Profile among women with coronary artery disease. Heart Lung. 1998;27:189-199.

44. O’Farrel P, Murray J, Huston P, LeGrand C, Adamo K. Sex differences in cardiac rehabilitation. Can J Cardiol. 2000;16:319-325.

45. Horsten M, Mittleman A, Wamala SP, Schenck-Gustafsson K, OrthGomér K. Depressive symptoms and lack of social integration in relation to prognosis of CHD in middle-aged women: the Stockholm Female Coronary Risk Study. Eur Heart J. 2000;21:1072-1080.

46. Fridlund B and the MISS-W Study Group. Social network and support among MI-women during the three months following upon a first myocardial infarction. Nurs Sci Res Nordic Count. 1997;17:9-14.

47. Ashton KC. Perceived learning needs of men and women after myocardial infarction. J Cardiovasc Nurs 1997; 12:93-100

48. Limacher MC. Exercise and rehabilitation in women. Indications and outcomes. Cardiol Clin. 1998;16:2736

49. Halm M, Penque S, Doll N, Beahrs M. Women and cardiac rehabilitation: referral and compliance patterns. J Cardiovasc Nurs. 1999; 13:83-92.

50. King KM, Humen DP, Teo KK. Cardiac rehabilitation: the forgotten intervention. Can J Cardiol. 1999;15:979-985.

51. Tardivel J. Gender differences in relation to motivation and compliance in cardiac rehabilitation. Nurs Crit Care. 1998:3:214-219.

52. Lesperance F, Frasure-Smith N Depression in patients with cardiac disease; a practical review. $\mathrm{J}$ Psychosom Res. 2000;48:379-391.

53. Linden W. Psychological treatments in cardiac rehabilitation: Review of rationales and outcomes. J Psychosom Res. 2000;48:443-454.

54. Schuster PM, Wright C, Tomich P. Gender differences in the outcomes of participants in home programs compared to those in structured cardiac rehabilitation programs. Rehabil Nurs. 1995;20:93-101.

55. Karlberg L, Krakau I, Unden AL. Type A behavior intervention in primary health care reduces hostility and time pressure: a study in Sweden. Soc Sci Med. 1998;46:397-402

56. Deshotels A, Planchock N, Dech $\mathrm{Z}$, Prevost S. Gender differences in perceptions of quality of life in cardiac rehabilitation patients. $\mathrm{J}$

Cardiopulm Rehabil. 1995;15:143148.

57. Warner JG Jr, Brubaker PH, Zhu $\mathrm{Y}$ et al. Long-term (5-year) changes in HDL cholesterol in cardiac rehabilitation patients: Do sex differences exist? Circulation. 1995;92:773-777. 